ASTHMA

\title{
Association of asthma and hay fever with irregular menstruation
}

\author{
C Svanes, F Gomez Real, T Gislason, C Jansson, R Jögi, E Norrman, L Nyström, K Torén, \\ E Omenaas
}

Thorax 2005;60:445-450. doi: 10.1136/thx.2004.032615

See end of article for authors' affiliations .....................

Correspondence to: Dr C Svanes, Department of Thoracic Medicine, Haukeland Hospital, 5021 Bergen, Norway; cecilie. svanes@med.vib.no

Received 5 August 2004 Accepted 17 February 2005
Background: There is some evidence that asthmatic women are more likely to have abnormal sex hormone levels. A study was undertaken to determine whether asthma and allergy were associated with irregular menstruation in a general population, and the potential role of asthma medication for this association. Methods: A total of 8588 women (response rate 77\%) participated in an 8 year follow up postal questionnaire study of participants of the ECRHS stage I in Denmark, Estonia, Iceland, Norway, and Sweden. Only non-pregnant women not taking exogenous sex hormones were included in the analyses $(n=6137)$.

Results: Irregular menstruation was associated with asthma (OR $1.54(95 \% \mathrm{Cl} 1.11$ to 2.13$)$ ), asthma symptoms (OR 1.47 (95\% Cl 1.16 to 1.86$)$ ), hay fever (OR 1.29 (95\% Cl 1.05 to 1.57$)$ ), and asthma preceded by hay fever (OR 1.95 (95\% Cl 1.30 to 2.96)) among women aged $26-42$ years. This was also observed in women not taking asthma medication (asthma symptoms: OR 1.44 (95\% Cl 1.09 to 1.91); hay fever: OR 1.27 (95\% Cl 1.03 to 1.58); wheeze preceded by hay fever: OR 1.76 (95\% Cl 1.18 to 2.64$)$ ). Irregular menstruation was associated with new onset asthma in younger women (OR 1.58 (95\% Cl 1.03 to 2.42$)$ ) but not in women aged $42-54$ years (OR $0.62(95 \% \mathrm{Cl} 0.32$ to 1.18$)$ ). The results were consistent across centres.

Conclusions: Younger women with asthma and allergy were more likely to have irregular menstruation. This could not be attributed to current use of asthma medication. The association could possibly be explained by common underlying metabolic or developmental factors. The authors hypothesise that insulin resistance may play a role in asthma and allergy.
$\mathrm{T}$ here are many pieces of evidence that indicate a role for female sex hormones in asthma and allergy. This relationship is, however, poorly understood and in most aspects also poorly investigated. Studies of women indicate complex and contradictory associations of asthma with natural hormonal status like puberty, ${ }^{1}$ pregnancy, ${ }^{2}$ menstrual cycle, ${ }^{1}$ and menopause, ${ }^{3}$ and with treatment with female sex hormones. ${ }^{4}$ Kos-Kudla et $a l^{5}$ measured circadian variation in female sex hormones in 55 asthmatic and 20 non-asthmatic women and concluded that sex steroid hormones were more often out of range in women with asthma. This was most pronounced in women taking inhaled steroids but was also evident in those not taking inhaled steroids. Ravelo et $a l^{6}$ found abnormalities in the level of one or more sex hormones in 24 of 30 asthmatic women. A study of women referred for anovulatory infertility showed that asthma medication before age 21 was 2.5 times more common than in the general population. ${ }^{7}$ These indications that asthma in women may be associated with an imbalance in sex hormones have important implications, particularly with regard to the role of asthma medication, and advocate further investigation.

Non-pregnant and non-lactating women of reproductive age may have irregular menstruation for a variety of reasons, polycystic ovary syndrome being the most common with a population frequency of $5-10 \%{ }^{8}$ Polycystic ovary syndrome is a chronic disorder of ovarian function that is characterised by irregular menstruation, hyperandrogenism, and subfertility. ${ }^{9}$ The disorder is a manifestation of metabolic syndrome. ${ }^{8}$ Endometriosis occurs in $3-10 \%$ of young women ${ }^{10}$ and is characterised by dysmenorrhoea and infertility, but may also cause irregular menstrual periods. ${ }^{11}$ Severe stress, serious disease, anorexia nervosa, and drug addiction are other causes of irregular menstruation. ${ }^{12}$
We investigated whether asthmatic women in a general population more often had irregular menstruation. To the authors' knowledge, this has not been studied previously. In particular, we wanted to investigate the role of asthma medication. Based on data from a large Northern European population based cohort, this paper presents an analysis of the association of asthma and hay fever with irregular menstruation in women aged 25-54 years.

\section{METHODS}

Data collection

The Respiratory Health in Northern Europe (RHINE) ${ }^{13}$ is a follow up study of subjects from seven Northern European centres who participated in the European Community Respiratory Health Survey (ECRHS) stage 1, a study that took place in 1990-4. ${ }^{14}$ In stage I of the ECRHS men and women aged 20-44 years were randomly selected from the population registers from each participating centre. A postal questionnaire was sent to 3000-4000 persons in each centre. The target population for the RHINE study was the responders from Reykjavik in Iceland, Bergen in Norway, Umeå, Uppsala and Göteborg in Sweden, Aarhus in Denmark and Tartu in Estonia ( $\mathrm{n}=21$ 802; response rate 83.7\%). These (excluding 264 deaths) were sent a postal questionnaire in 1999-2001. Persons not responding to the first mailing were sent two reminders. A total of 16190 persons answered the questionnaire including 8588 women (response rate $77 \%$ ) born between 1945 and 1973. The study was approved by the local ethics committees in all the study centres.

The first part of the questionnaire contained 12 questions that were identical with those asked in the ECRHS stage 1 (available at www.ecrhs.org). These items covered respiratory 
Box 1 Questions in the ECRHS I screening

\section{questionnaire}

- Q1: Have you had wheezing or whistling in your chest at any time in the last 12 months? (If "no", go to question 2; if "yes" answer questions 1.1 and 1.2)

- Q1.1 Have you been at all breathless when the wheezing noise was present?

- Q1.2 Have you had this wheezing or whistling when you did not have a cold?

- Q2: Have you woken up with a feeling of tightness in your chest at any time in the last 12 months?

- Q3: Have you been woken by an attack of shortness of breath at any time in the last 12 months?

- Q4: Have you been woken by an attack of coughing at any time in the last 12 months?

- Q5 Have you had an attack of asthma in the last 12 months?

- Q6: Are you currently taking any medicine (including inhalers, aerosols or tablets) for asthma?

- Q7: Do you have hay fever or nasal allergies?

symptoms during the last 12 months, current asthma medication, and current hay fever (box 1). "Asthma" was defined as having had asthma attacks during the previous 12 months (Q5) and/or currently taking asthma medication (Q6). The asthma symptoms Q1 to Q6 are grouped as defined in footnotes to the tables. "New" symptoms were defined as having answered "no" to a question in the first survey and "yes" to the same question in the follow up survey. "Persistent" symptoms were defined as having answered "yes" to a question in both surveys.

The second part of the questionnaire included 52 items covering various aspects including hormonal status in women. The women were asked whether their menstrual periods were regular ("Do you have regular menstrual periods?" yes/no/don't know). Women answering "no" were defined as having irregular menstrual periods $(n=1975)$, women answering "don't know" were excluded from the analysis, as were women not responding to the question $(n=288)$. Pregnant women $(n=260)$, post-menopausal women (defined as not having had menstruation during the previous 6 months, $\mathrm{n}=980)$, and women currently taking oral contraceptives $(n=1071)$ or hormonal replacement therapy $(n=655)$ were also excluded from the analyses. Thus, 6137 non-pregnant women of reproductive age not taking exogeneous sex hormones were left for analysis.

\section{Statistical analysis}

Logistic regression analyses were used to assess the effects of irregular menstruation on measures of asthma and hay fever. Separate analyses of women not taking asthma medications were carried out in order to exclude the potential influence of asthma medication on the menstrual cycle. Multiple linear regression analyses of the effects of irregular menstruation on the number of symptoms were performed in order to increase the strength in analyses of new and persistent symptoms which were less common outcome measures. Adjustments were made for age ( 5 year categories), body mass index (quartiles), smoking habits (never, ex- and current smoking), social class (current type of dwelling), and study centre. A socioeconomic index based on occupation

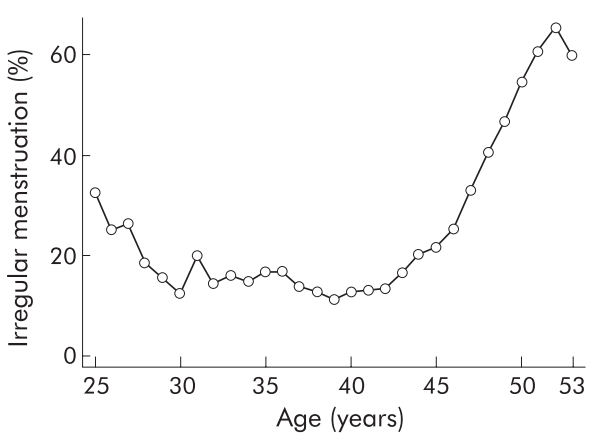

Figure 1 Prevalence of irregular menstruation by age in seven population samples including 8588 women from Northern Europe.

was available for four centres; adjustment for this variable did not influence the results. Potential heterogeneity between centres was studied by meta-analyses. ${ }^{15}$ The biological background for irregular menstruation was considered essentially different in younger and older women, so analyses were stratified by age 43 years, the age when irregular menstruation increased in frequency due to the natural approach of menopause (fig 1). ${ }^{10}$

The analyses were carried out using the statistical software program Stata 7.0 (Stata Corporation, College Station, Texas, USA).

\section{RESULTS}

The prevalence of irregular menstruation was $23 \%, 15 \%$ in those aged 25-42 years and 37\% among women aged 4354 years (table 1). Among the younger women, irregular menstruation was more common in those with a higher body mass index and in the shortest and tallest women, while in older women irregular menstruation was associated with more smoking (data not given).

The prevalence of asthma and allergy was higher in women with irregular menstrual periods than in those with regular menstruation in the age group 25-42 years (table 2). Adjusted for smoking habits, body mass index, social class, age and study centre, irregular menstruation was significantly associated with increased risk for asthma, asthma symptoms, and hay fever (table 2). The associations were particularly strong for asthma or wheeze preceded by hay fever. Analysing age at onset of doctor diagnosed asthma involved relatively small numbers and the associations with irregular menstruation did not reach statistical significance, but the size of the estimates appeared to be similar for asthma with onset in childhood (OR 1.33, 95\% CI 0.71 to 2.49 ), in adolescence (OR $1.49,95 \%$ CI 0.86 to 2.59 ), and in adulthood (OR 1.20, 95\% CI 0.78 to 1.84). Excluding 259 women currently using asthma medication, irregular menstruation was still associated with symptoms of asthma and allergy, although there was a tendency towards weaker associations (table 2).

In women aged 43-54 years the prevalence of irregular menstruation increased with age (fig 1), consistent with an increasing number of women entering the perimenopausal transition. In this age group there was no association between irregular menstruation and new onset asthma or symptoms, in contrast to the increase in new onset asthma and higher number of new onset asthma symptoms associated with irregular menstruation among women aged 25-42 years (table 3 ). These differences between the age groups were significant or of borderline significance (new onset asthma: $p_{\text {interaction }}=0.008$; number of new onset asthma symptoms: $p_{\text {interaction }}=0.057$ ). The associations with 
Table 1 Characteristics of the 8588 women participating in RHINE

\begin{tabular}{|c|c|c|c|c|c|c|c|c|}
\hline & $\begin{array}{l}\text { Aarhus } \\
(n=1362)\end{array}$ & $\begin{array}{l}\text { Reykjavik } \\
\text { ( } n=1075 \text { ) }\end{array}$ & $\begin{array}{l}\text { Bergen } \\
(n=1301)\end{array}$ & $\begin{array}{l}\text { Gøteborg } \\
(n=1185)\end{array}$ & $\begin{array}{l}\text { Umeå } \\
(n=1356)\end{array}$ & $\begin{array}{l}\text { Uppsala } \\
\text { ( } n=1351)\end{array}$ & $\begin{array}{l}\text { Tartu } \\
(\mathrm{n}=958)\end{array}$ & $\begin{array}{l}\text { All } \\
(n=8588)\end{array}$ \\
\hline Irregular menstruation (\%) & 20 & 20 & 21 & 25 & 25 & 28 & 21 & 23 \\
\hline$<43$ years $(\%)$ & 11 & 12 & 13 & 14 & 17 & 19 & 20 & 15 \\
\hline$\geqslant 43$ years $(\%)$ & 36 & 33 & 35 & 43 & 37 & 43 & 26 & 37 \\
\hline Oral contraceptives (\%) & 14 & 19 & 8.6 & 14 & 10 & 16 & 10 & 13 \\
\hline Pregnant (\%) & 5.6 & 3.8 & 3.3 & 2.9 & 2.4 & 2.1 & 1.8 & 3.2 \\
\hline Post-menopausal (\%) & 8.4 & 17 & 17 & 12 & 14 & 11 & 4.4 & 12 \\
\hline Hormone replacement therapy (\%) & 3.4 & 18 & 9.0 & 8.0 & 7.6 & 6.9 & 1.3 & 7.6 \\
\hline Asthma (\%) & 6.4 & 8.1 & 7.4 & 7.3 & 11 & 8.2 & 1.9 & 7.3 \\
\hline $\begin{array}{l}\text { Wheeze with shortness of breath and } \\
\text { when not having a cold (\%) }\end{array}$ & 9.1 & 9.6 & 15 & 13 & 13 & 11 & 7.3 & 11 \\
\hline Night time symptoms $(\%)^{*}$ & 8.3 & 11 & 14 & 15 & 14 & 13 & 22 & 14 \\
\hline Three or more asthma symptoms (\%)† & 14 & 12 & 16 & 16 & 18 & 15 & 15 & 15 \\
\hline Hay fever or nasal allergy (\%) & 23 & 25 & 26 & 27 & 24 & 24 & 23 & 24 \\
\hline Current smokers (\%) & 33 & 29 & 37 & 31 & 22 & 20 & 28 & 28 \\
\hline Median age (years) & 39 & 41 & 40 & 39 & 41 & 40 & 35 & 39 \\
\hline Median BMI $\left(\mathrm{kg} / \mathrm{m}^{2}\right)$ & 22.5 & 23.9 & 23.0 & 23.7 & 23.9 & 23.2 & 22.4 & 23.3 \\
\hline
\end{tabular}

*Waking with tightness in chest and/or waking with shortness of breath.

†Symptoms Q1-Q6: Wheeze, wheeze with shortness of breath, wheeze without cold, waking with tightness in chest, waking with shortness of breath, waking with cough, asthma attacks, current asthma medication.

persistent asthma and persistent asthma symptoms did not differ between the age groups (table 3 ).

The results were homogeneous across centres, as shown for the association of asthma with irregular menstruation in fig 2 $\left(p_{\text {heterogeneity }}=0.4\right)$. There were no significant interactions by body mass index or by current smoking status in the associations of asthma and allergy with irregular menstruation.

\section{DISCUSSION}

Women with asthma and allergy more often experienced irregular menstruation. This was observed consistently across centres in non-pregnant women of reproductive age in a population based Northern European cohort. The finding could not be attributed to current asthma medication influencing the menstrual cycle. In women aged 43 years or older, an age when irregular menstruation usually signals the normal approach of menopause, no association was found with new onset asthma. ${ }^{10}$ Thus, asthma and allergy appear to be associated with the pathological conditions underlying irregular menstruation. Our results are in accordance with previous studies reporting that asthmatic women more often have abnormal levels and cyclical patterns of sex steroid hormones, ${ }^{56}$ and that women taking asthma medication before the age of 21 years are more often referred for infertility. ${ }^{7}$

Bias related to healthcare seeking behaviour could explain our findings; women with irregular menstruation could see a doctor more often and have their asthma diagnosed more often. However, an association was also found for undiagnosed and untreated asthma symptoms, and there is no general awareness among physicians about a possible coexistence of hormonal factors in women and asthma and allergy. Increased health awareness among women with irregular menstruation-making them more aware of asthma symptoms or vice versa-could also contribute to the findings, but the association with childhood and adolescent onset asthma and the general high public awareness of asthma and allergy today argue against such bias.

A limitation to this study is the crude exposure information. Self-reported irregular menstruation was validated in the Nurses' Health Study and showed extremely high concordance. ${ }^{16}$ The frequency in our study population was similar to that reported in the literature. ${ }^{10}$ The causes of selfreported irregular menstruation in an epidemiological population study have not been described to the authors'

Table 2 Asthma and allergy as associated with irregular menstrual periods (using regular menstruation as the referent group) in non-pregnant women aged 25-42 years who were not taking exogenous sex hormones

\begin{tabular}{|c|c|c|c|c|c|c|}
\hline \multirow[b]{3}{*}{ Outcome variables } & \multicolumn{3}{|c|}{ All women $<\mathbf{4 3}$ years $(n=4077)$} & \multicolumn{3}{|c|}{ Excluding asthma medication users $(n=3848)$} \\
\hline & \multicolumn{2}{|c|}{ Prevalence of outcome (\%) } & \multirow[b]{2}{*}{ OR $(95 \% \mathrm{Cl})^{*}$} & \multicolumn{2}{|c|}{ Prevalence of outcome (\%) } & \multirow[b]{2}{*}{ OR $(95 \% \mathrm{Cl})^{*}$} \\
\hline & $\begin{array}{l}\text { Irregular } \\
\text { menstruation }\end{array}$ & $\begin{array}{l}\text { Regular } \\
\text { menstruation }\end{array}$ & & $\begin{array}{l}\text { Irregular } \\
\text { menstruation }\end{array}$ & $\begin{array}{l}\text { Regular } \\
\text { menstruation }\end{array}$ & \\
\hline Asthma & 9.2 & 6.3 & 1.54 (1.11 to 2.13$)$ & & & \\
\hline Asthma attacks & 5.0 & 3.5 & $1.49(0.97$ to 2.29$)$ & 1.6 & 1.2 & $1.48(0.70$ to 3.12$)$ \\
\hline Wheeze & 22.8 & 20.6 & $1.10(0.88$ to 1.37$)$ & 18.1 & 16.9 & $1.07(0.83$ to 1.37$)$ \\
\hline $\begin{array}{l}\text { Wheeze with shortness of breath and } \\
\text { when not having a cold }\end{array}$ & 10.2 & 7.8 & 1.40 (1.02 to 1.91$)$ & 6.5 & 4.8 & $1.44(0.96$ to 2.14$)$ \\
\hline Night time symptoms $\dagger$ & 18.7 & 12.7 & 1.53 (1.21 to 1.95$)$ & 15.0 & 10.5 & $1.42(1.08$ to 1.86$)$ \\
\hline Three or more asthma symptoms $\ddagger$ & 19.6 & 14.2 & $1.47(1.16$ to 1.86$)$ & 13.9 & 10.3 & 1.44 (1.09 to 1.91$)$ \\
\hline Hay fever or nasal allergy & 28.8 & 23.6 & 1.29 (1.05 to 1.57$)$ & 25.9 & 21.4 & 1.27 (1.03 to 1.58$)$ \\
\hline Asthma and hay fever & 6.1 & 4.1 & 1.53 (1.03 to 2.26$)$ & & & \\
\hline Wheeze and hay fever & 11.1 & 7.9 & $1.41(1.05$ to 1.90$)$ & 7.7 & 5.3 & $1.49(1.04$ to 2.15$)$ \\
\hline Asthma preceded by hay fever & 6.0 & 3.0 & 1.95 (1.30 to 2.96$)$ & & & \\
\hline Wheeze preceded by hay fever & 10.1 & 5.6 & 1.76 ( 1.28 to 2.43$)$ & 6.4 & 3.7 & $1.76(1.18$ to 2.64$)$ \\
\hline
\end{tabular}


Table 3 Associations of irregular menstruation with new and persistent asthma and asthma symptoms in 4077 women aged $25-42$ years and 2060 women aged 4354 years

\begin{tabular}{|c|c|c|}
\hline & $\begin{array}{l}\text { Asthma } \\
\text { OR }(95 \% \mathrm{Cl}) \dagger\end{array}$ & $\begin{array}{l}\text { Number of asthma symptoms* } \\
\text { (Coefficient) } \ddagger\end{array}$ \\
\hline \multicolumn{3}{|l|}{ New onset } \\
\hline Age $25-42$ years & 1.58 (1.03 to 2.42$)$ & $0.10(0.00-0.19)$ \\
\hline Age $43-54$ years & 0.62 (0.32 to 1.18$)$ & $-0.04(-0.16-0.08)$ \\
\hline \multicolumn{3}{|l|}{ Persistent } \\
\hline Age $25-42$ years & 1.43 (0.89 to 2.30$)$ & $0.15(0.06-0.25)$ \\
\hline Age $43-54$ years & 1.41 (0.79 to 2.51$)$ & $0.11(-0.02-0.23)$ \\
\hline \multicolumn{3}{|c|}{$\begin{array}{l}\text { *Symptoms Q1-Q6: Wheeze, wheeze with shortness of breath, wheeze without cold, waking with tightness in } \\
\text { chest, waking with shortness of breath, waking with cough, asthma attacks, current asthma medication. } \\
\text { †From logistic regression models with adjustment for smoking habits, type of dwelling, BMI, age, and centre. } \\
\text { †From multiple linear regression model with adjustment for smoking habits, type of dwelling, BMl, age, and centre. }\end{array}$} \\
\hline
\end{tabular}

knowledge, but polycystic ovary syndrome accounts for 73$90 \%$ of oligomenorrhoea or amenorrhoea cases in women referred to a specialist. ${ }^{17-19}$ In the Nurses' Health Study selfreported irregular menstruation was related to cardiovascular disease $^{16}$ and to type 2 diabetes, ${ }^{20}$ both suggesting a role for polycystic ovary syndrome.

Lactation is a non-pathological cause of irregular menstruation about which little is known. Based on the number of pregnant women in the study population and the duration of breast feeding common in the study area, we estimate that $15-20 \%$ of cases of irregular menstruation among the younger women may be related to lactation. Asthma and allergy do not seem to be more common among lactating women. $^{21}{ }^{22}$ Thus, the true association with irregular menstruation due to pathological conditions may be stronger than that presented in this analysis, due to attenuation by inclusion of lactating women without increased risk.

There are three possible theoretical reasons for a valid association of irregular menstruation and asthma: (1) asthma or asthma medication may cause disturbances in the menstrual cycle, (2) irregular menstruation or its treatment may cause asthma, and (3) common aetiological factors may cause both irregular menstruation and asthma/ allergy. Considering the first, oral steroids used in the treatment of asthma probably do influence the cyclic variation and levels of sex hormones. ${ }^{5}$ Kos-Kudla et al found that inhaled steroids had an effect on the levels and circadian

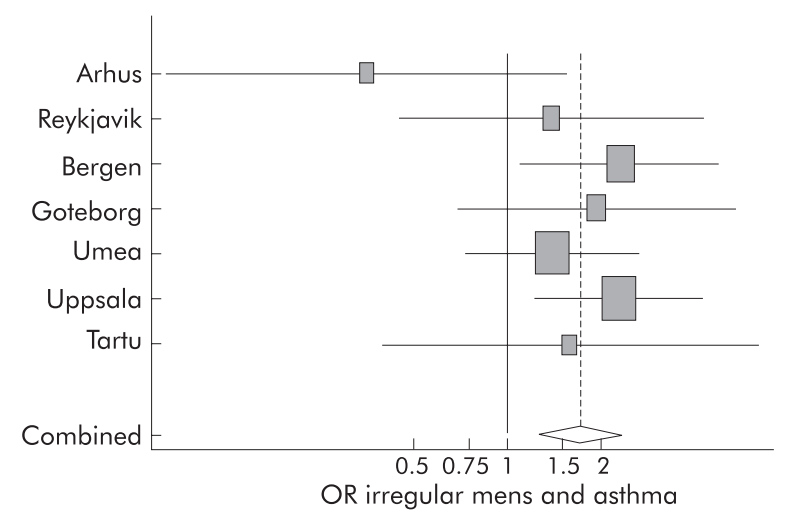

Figure 2 Odds ratios for the association of irregular menstruation with asthma (current asthma medication and/or asthma attacks in previous 12 months) by centre, including 4077 non-pregnant women aged 2543 years who were not taking exogenous sex hormones. Adjustment within centre for body mass index, smoking, social class, and age. For each centre horizontal lines indicate $95 \% \mathrm{Cl}$. For combined odds ratio the diamond indicates $95 \% \mathrm{Cl}$ from the model with the centre as random effect. The size of each square is proportional to the sample size. variation of sex steroid hormones, but an effect was also found in asthmatic women not taking asthma medication. ${ }^{5}$ Only 259 of the women in our study used any asthma medication and, when these were excluded, asthma symptoms and hay fever were still significantly related to irregular menstruation. Thus, adverse effects of current asthma medication cannot explain our findings. The stress of asthma might be suspected to cause disturbances in the menstrual cycle. However, asthma of such severity is usually treated medically in Northern Europe and current stress could not explain the associations with childhood and adolescent asthma.

Secondly, the sex hormone imbalance underlying irregular menstruation or its treatment might cause asthma and allergy. The literature gives several pieces of evidence that female sex hormones do influence physiological processes involved in asthma and allergy. ${ }^{23}$ Furthermore, women with irregular menstruation may be treated with hormonal cures in order to induce pregnancy or with oral contraceptives due to hyperandrogenism or dysmenorrhoea. Asthma and allergy could be side effects of exogenous sex hormones, ${ }^{4}$ but women taking oral contraceptives at the time of the survey were excluded from the analyses. These explanations seem unlikely as irregular menstruation was associated with asthma starting in childhood as well as with asthma starting after puberty.

Finally, the association of irregular menstruation with asthma and allergy could be explained by common aetiological factors. Developmental disadvantage in early life such as poor intrauterine conditions is related both to an increased risk for asthma ${ }^{24}$ and to hormonal imbalance. ${ }^{25-27}$ Common underlying metabolic disease is another possible explanation. Irregular menstruation may be caused by polycystic ovary syndrome, a manifestation of metabolic syndrome that can be treated with insulin sensitising drugs such as metformin. ${ }^{8}$

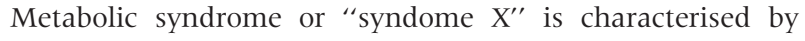
insulin resistance and dyslipidaemia, and is a causal factor of major importance for cardiovascular disease and several other diseases of the western civilisation. ${ }^{28}$ There are no studies of metabolic syndrome and asthma or allergy, but several studies have reported associations between lung function and insulin resistance..$^{29-35}$ The authors hypothesise that insulin resistance may have a role in the causation of asthma and allergy as well as in polycystic ovary syndrome, thereby explaining the association of asthma and hay fever with irregular menstruation. This hypothesis could possibly help to clarify the complex and contradictory findings concerning asthma and other aspects of hormonal status in women. It could also explain the association of asthma with body mass index ${ }^{36-38}$ and the complex associations of asthma with dietary factors. ${ }^{39}$ 
A study of women with endometriosis showed a higher prevalence of asthma and allergy than that described for the general population, ${ }^{11}$ and leukotriene antagonists intended for asthma treatment have been used in the treatment of endometriosis. ${ }^{40}{ }^{41}$ Endometriosis and asthma/allergy may therefore have common inflammatory features which could explain some of the association between irregular menstruation and asthma/allergy. However, the disease accounts for a relatively small number of women with irregular menstruation. Irregular menstrual periods may be due to poor general health, but this is not very common and severely stressed or ill women are less likely to have participated twice in our investigation. In any case, there may be subgroups of women with irregular menstruation with a strongly increased risk for asthma and allergy, and this should be investigated further.

In conclusion, this study is the first to show that asthma and allergy are related to irregular menstrual periods. This was observed in a general population, was consistent between a number of study centres, and is in agreement with two reports of abnormal sex hormone levels in women with asthma. ${ }^{5}$ These findings raise the question whether women with asthma have a higher incidence of subfertility problems as indicated in a previous study. ${ }^{7}$ Our study indicates that current asthma medication could not be blamed for the effect. However, the effects of asthma medication in childhood or adolescence need further investigation. The association of asthma with irregular menstruation may give a clue to further understanding the physiology of asthma. We believe that the association may be explained by common aetiological factors, and speculate that insulin resistance might have a role in the multifactorial aetiology of asthma and allergy, or that a developmental disadvantage may explain the association of asthma and allergy with irregular menstruation.

\section{ACKNOWLEDGEMENTS}

The authors acknowledge the helpful contributions made by the following scientists in the RHINE study group: T Blöndal, U S Björnsdottir, G Boman, B Forsberg, D Gislason, A Gulsvik, M Gunnbjörnsdottir, E Juel Jensen, M-C Ledin, L Lillienberg, B Lundbäck, B N Lærum, D Norbäck, E Norrman, A-C Olin, E Rydén, U Spetz-Nyström, C K Stenudd, M Söderberg, J Talvik, A Tunsäter, L T Wenzel, G Wieslander.

\section{Authors' affiliations \\ C Svanes, F G Real, Institute of Medicine, University of Bergen, 5021 Bergen, Norway}

C Svanes, E Omenaas, Department of Thoracic Medicine, Haukeland University Hospital, 5021 Bergen, Norway

F G Real, Department of Gynaecology and Obstetrics, Haukeland University Hospital, 5021 Bergen, Norway

T Gislason, Department of Pulmonary Medicine, Landspitali University Hospital, 105 Reykjavik, Iceland

C Jansson, Department of Medical Sciences: Respiratory Medicine and Allergology, Uppsala University, 77185 Uppsala, Sweden

R Jögi, Foundation Tartu University Clinics, Lung Clinic, 51014 Tartu, Estonia

E Norrman, Department of Pulmonary Medicine and Allergology, Umeå University, 90185 Umeå, Sweden

L Nyström, Department of Public Health, Clinical Medicine,

Epidemiology, Umeå University, 90185 Umeå, Sweden

K Torén, Department of Occupational and Environmental Medicine,

Sahlgrenska University Hospital, 41266 Göteborg, Sweden

The study was supported financially by the Icelandic Research Council, the Swedish Heart and Lung Foundation, the Varrdal Foundation for Health Care Science and Allergy Research, the Swedish Association Against Asthma and Allergy, the Norwegian Research Council project 135773/330, the Norwegian Asthma and Allergy Association, the Danish Lung Association and the Estonian Science Foundation grant no 4350 .
Competing interests: Cecilie Svanes has received $5000 \mathrm{Nkr}$ (approximately 600 Euro) from MSD in January 2004 for giving a speech on asthma in women and an independent educational grant of 100000 $\mathrm{Nkr}$ (approximately 11800 Euro) from GlaxoSmithKline in 2002 for the project "Asthma in women".

\section{REFERENCES}

1 Becklake MR, Kauffmann F. Gender differences in airway behaviour over the human life span. Thorax 1999;54:1119-38.

2 Nelson-Piercy C. Asthma in pregnancy. Thorax 2001;56:325-8.

3 Troisi RJ, Speizer FE, Willett WC, et al. Menopause, postmenopausal estrogen preparations, and the risk of adult-onset asthma. A prospective cohort study. Am J Respir Crit Care Med 1995; 152:1183-8.

4 Forbes L. Do exogenous oestrogens and progesterone influence asthma? Thorax 1999:54:265-7.

5 Kos-Kudla B, Ostrowska Z, Marek B, et al. Hormone replacement therapy in postmenopausal asthmatic women. J Clin Pharm Ther 2000;25:461-6.

6 Rubio Ravelo L, Gago Rodriguez B, Almirall Collazo JJ, et al. Comparative study of progesterone, estradiol and cortisol concentrations in asthmatic and non-asthmatic women. Allergol Immunopathol (Madr) 1988;16:263-6.

7 Grodstein F, Goldman MB, Ryan L, et al. Self-reported use of pharmaceuticals and primary ovulatory infertility. Epidemiology 1993;4:151-6.

8 Harborne L, Fleming R, Lyall H, et al. Descriptive review of the evidence for the use of metformin in polycystic ovary syndrome. Lancet, 2003:361:1894-901.

9 Speroff L, Glass RH, Kase NG. Anovulation and the polycystic ovary. In: Mitchell C, eds. Clinical gynecologic endocrinology and infertility.6th ed. Baltimore: Lippincott Williams \& Wilkins, 1999:487-522.

10 Speroff L, Glass RH, Kase NG. Regulation of the menstrual cycle. In: Mitchell C, eds. Clinical gynecologic endocrinology and infertility.6th ed. Baltimore: Lippincott Williams \& Wilkins, 1999:201-46.

11 Sinaii N, Cleary SD, Ballweg ML, et al. High rates of autoimmune and endocrine disorders, fibromyalgia, chronic fatigue syndrome and atopic diseases among women with endometriosis: a survey analysis. Hum Reprod 2002;17:2715-24.

12 Speroff L, Glass RH, Kase NG. Amenorrhea. In: Mitchell C, eds. Clinical gynecologic endocrinology and infertility.6th ed. Baltimore: Lippincott Williams \& Wilkins, 1999:421-86.

13 Gunnbjörnsdottir M, Omenaas E, Gislason T, et al. Obesity and nocturnal GER are related to the onset of asthma and respiratory symptoms. Eur Respir J 2004;24:116-21.

14 Burney PG, Luczynska C, Chinn S, et al. The European Community Respiratory Health Survey. Eur Respir J 1994;7:954-60.

15 DerSimonian R, Laird N. Meta-analysis in clinical trials. Control Clin Trials 1986;7:177-88.

16 Solomon CG, Hu FB, Dunaif A, et al. Menstrual cycle irregularity and risk for future cardiovascular disease. J Clin Endocrinol Metab 2002;87:2013-7.

17 Adams J, Polson DW, Franks S. Prevalence of polycystic ovaries in women with anovulation and idiopathic hirsutism. BMJ (Clin Res Ed) 1986:293:355-9.

18 Franks S. Polycystic ovary syndrome. N Engl J Med 1995;333:853-61.

19 Hull MG. Epidemiology of infertility and polycystic ovarian disease: endocrinological and demographic studies. Gynecol Endocrinol 1987; 1:235-45.

20 Solomon CG, Hu FB, Dunaif A, et al. Long or highly irregular menstrual cycles as a marker for risk of type 2 diabetes mellitus. JAMA $2001 ; 286: 2421-6$.

21 Schatz M, Harden K, Forsythe A, et al. The course of asthma during pregnancy, post partum, and with successive pregnancies: a prospective analysis. J Allergy Clin Immunol 1988;81:509-17.

22 Olesen C, Steffensen FH, Nielsen GL, et al. Drug use in first pregnancy and lactation: a population-based survey among Danish women. The EUROMAP group. Eur J Clin Pharmacol 1999;55:139-44.

23 Balzano G, Fuschillo S, Melillo G, et al. Asthma and sex hormones. Allergy 2001;56:13-20.

24 Svanes C, Omenaas E, Heuch JM, et al. Birth characteristics and asthma symptoms in young adults: results from a population-based cohort study in Norway. Eur Respir J 1998;12:1366-70.

25 Hokken-Koelega AC. Timing of puberty and fetal growth. Best Pract Res Clin Endocrinol Metab 2002;16:65-71.

26 Lithell HO, McKeigue PM, Berglund L, et al. Relation of size at birth to noninsulin dependent diabetes and insulin concentrations in men aged 50-60 years. BMJ 1996;312:406-10.

27 Lawlor DA, Ebrahim S, Smith GD. Associations of measures of lung function with insulin resistance and type 2 diabetes: findings from the British Women's Heart and Health Study. Diabetologia 2004;47:195-203.

28 Cordain L, Eades MR, Eades MD. Hyperinsulinemic diseases of the western civilization: more than just syndrome X. Comp Biochem Physiol A Mol Integr Physiol 2003;136:95-112.

29 Lange P, Groth S, Kastrup J, et al. Diabetes mellitus, plasma glucose and lung function in a cross-sectional population study. Eur Respir $J$ 1989;2:14-9.

30 Engstrom G, Hedblad B, Nilsson P, et al. Lung function, insulin resistance and incidence of cardiovascular disease: a longitudinal cohort study. J Intern Med 2003;253:574-81

31 Engstrom G, Janzon L. Risk of developing diabetes is inversely related to lung function: a population-based cohort study. Diabet Med 2002;19:167-70. 
32 Lazarus R, Sparrow D, Weiss ST. Impaired ventilatory function and elevated insulin levels in nondiabetic males: the Normative Aging Study. Eur Respir J 1998; 12:635-40.

33 Walter RE, Beiser A, Givelber RJ, et al. Association between glycemic state and lung function: the Framingham Heart Study. Am J Respir Crit Care Med 2003;167:911-6.

34 Davis WA, Knuiman M, Kendall P, et al. Glycemic exposure is associated with reduced pulmonary function in type 2 diabetes: the Fremantle Diabetes Study. Diabetes Care 2004; 27:752-7.

35 Barrett-Connor E, Frette C. NIDDM, impaired glucose tolerance, and pulmonary function in older adults. The Rancho Bernardo Study. Diabetes Care 1996;19:1441-4.

36 Chinn S. Obesity and asthma: evidence for and against a causal relation. $J$ Asthma 2003:40:1-16.
37 Camargo CA Jr, Weiss ST, Zhang S, et al. Prospective study of body mass index, weight change, and risk of adult-onset asthma in women. Arch Intern Med 1999; 159:2582-8.

38 Shaheen SO, Sterne JA, Montgomery SM, et al. Birth weight, body mass index and asthma in young adults. Thorax 1999;54: 396-402.

39 Romieu I, Trenga C. Diet and obstructive lung diseases. Epidemiol Rev 2001;23:268-87.

40 Harel Z, Lilly C, Riggs S, et al. Urinary leukotriene (LT) E(4) in adolescents with dysmenorrhea: a pilot study. J Adolesc Health 2000;27:151-4.

41 Abu JI, Konje JC. Leukotrienes in gynaecology: the hypothetical value of antileukotriene therapy in dysmenorrhoea and endometriosis. Hum Reprod Update 2000;6:200-5.

\section{LUNG ALERT}

Intrapleural streptokinase does not improve outcomes in empyema

$\Delta$ Maskell NA, Davies CWH, Nunn AJ, et al. UK controlled trial of intrapleural streptokinase for pleural infection. N Engl J Med 2005;352:865-74

ntrapleural fibrinolytic agents have been advocated in the management of pleural infection in many respiratory society guidelines. However, the evidence base for this recommendation stems from case series and small trials which do not have adequate statistical power.

The MISTl study was a double blind, randomised, controlled trial with 454 patients enrolled in 52 centres in the UK. The inclusion criteria were the presence of macroscopically purulent pleural fluid, positive pleural fluid bacterial culture or gram stain, or a pleural fluid $\mathrm{pH}<7.2$. All patients received IV antibiotics and underwent chest tube insertion. Patients enrolled received either 250000 IU streptokinase administered through the chest tube every 12 hours (maximum 6 doses) or matched placebo. The primary outcome measure used was the number of patients who died or required surgical drainage at 3 months. Secondary end points included death or surgery at 12 months, duration of hospital stay, the severity of residual chest radiographic changes, and dynamic lung volumes 3 months after randomisation. Also noted were levels of antistreptokinase antibody from baseline to 3 months and any bleeding after surgical drainage of the empyema.

Statistical analysis was performed on 430 subjects (the 24 excluded either died, underwent surgery, or withdrew consent before receiving the drug). Results evaluated after 3 and 12 months revealed, rather unexpectedly, that there was no improvement in outcomes with streptokinase. In fact, there was an increase in adverse events-notably chest pain and allergic reactions. Also, the elevated antibody response raises concerns for receiving streptokinase in any future thrombotic events. The authors therefore conclude that intrapleural streptokinase should generally be avoided in pleural infections.

M Menon

Specialist Registrar in Respiratory Medicine, Princess Alexandra Hospital, Harlow, Essex, UK mkmenon@doctors.org.uk 